International Journal of Health Sciences
Available online at www.Sciencescholar.us
Vol. 5 No. 2, August 2021, pages: 53-61
e-ISSN: 2550-696X, p-ISSN: 2550-6978
https://doi.org/10.29332/ijhs.v5n2.1148

\title{
Validity of Neutrophil Lymphocyte Count Ratio in Neonatal Sepsis
}

\begin{abstract}
(1) CrossMark
Heriyanto Lim a, Made Sukmawati b, Wayan Dharma Artana c, Made Kardana d, Putu Junara Putra e

Manuscript submitted: 27 March 2021, Manuscript revised: 18 April 2021, Accepted for publication: 9 May 2021

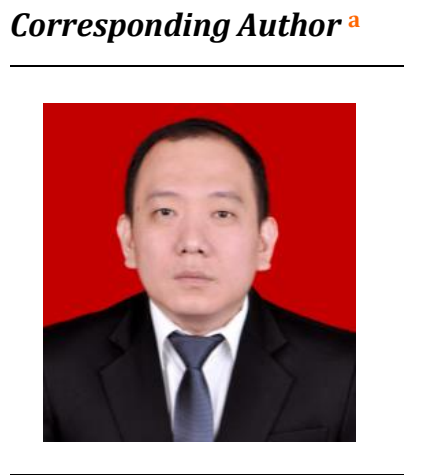

Keywords

neonatal sepsis;

neutrophil-lymphocyte

\section{Abstract}

Sepsis is a major problem in neonatal care that has not been resolved. This condition is becoming one of major cause of morbidity and mortality in neonates especially in developing countries. Neutrophil lymphocytes count ratio (NLCR) is a new marker of infection that is easy, rapid method and less expensive that can be done in limited health care facilities. A retrospective study with cross-sectional design was conducted on 84 neonates with sepsis. The data was collected from medical records from April 2018 to September 2018 in Perinatology Division Sanglah hospital. ROC curve is was done to determine the value cut-off point, sensitivity and specificity of NLCR. With cut-off point of 2.31 NLCR has prevalence, sensitivity, specificity, positive predictive value (PPV) and negative pedictive value (NPV) of $26.1 \%, 81.8 \%$, $66.1 \%, 46.1 \%$ and $91.1 \%$. NLCR is the potential to be used in the diagnosis of neonatal sepsis.
\end{abstract}

count ratio;

procalcitonin;

\section{Contents}

Abstract

1 Introduction.

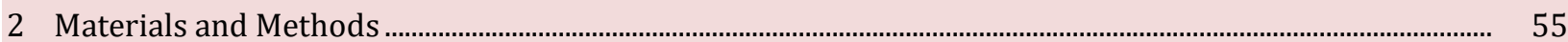

${ }^{\text {a }}$ Department of Child Health, Medical School of Udayana Univesity, Denpasar, Indonesia

b Department of Child Health, Medical School of Udayana Univesity, Denpasar, Indonesia

c Department of Child Health, Medical School of Udayana Univesity, Denpasar, Indonesia

d Department of Child Health, Medical School of Udayana Univesity, Denpasar, Indonesia

e Department of Child Health, Medical School of Udayana Univesity, Denpasar, Indonesia 


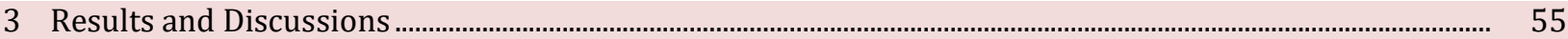

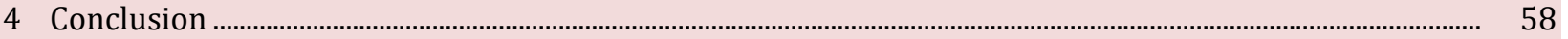

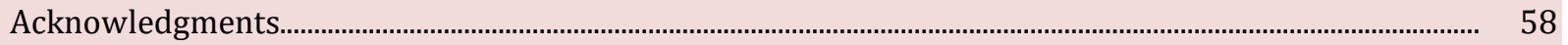

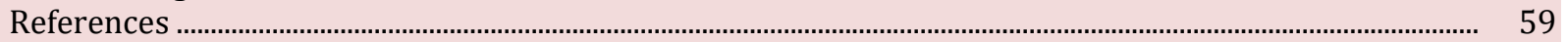

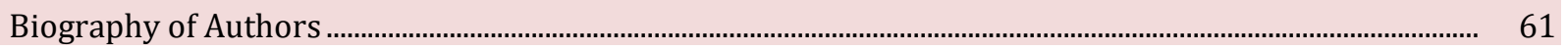

\section{Introduction}

Neonatal sepsis is a serious blood bacterial infection which commonly present as systemic signs of infection and bacteremia in the first month of life. It is a mayor causes of morbidity and mortality in neonates especially in developing countries. According to World Health Organization (WHO) in 2006 26\% of neonatal deaths occured due to infection (World Health Organization, 2006). Around 30-50\% of newborn deaths in developing countries are caused by sepsis (Sankar et al., 2008). Data from the Health Ministry of Republic of Indonesia's Fundamental Health Research (Riskesdas) in 2007 revealed sepsis as the risk factor that cause neonatal death at the age of $0-6$ days $12 \%$ and $20.5 \%$ of neonatal death at 7-28 days (Department of Health, 2007). Research by (Kardana, 2011), in Sanglah General Hospital Denpasar in 2008 found mortality in neonatal sepsis was $28.3 \%$.

The signs and symptoms of neonatal sepsis are nonspecific. These include fever or hypothermia, respiratory distress including cyanosis and apnea, feeding difficulties, lethargy or irritability, hypotonic, seizures, bulging fontanel, poor perfusion, bleeding problems, abdominal distention, hepatomegaly, guaiac positive stools, and unexplained jaundice (Shah et al., 2014).

To support the history and physical examination results, there are several examinations that can be used to diagnose neonatal sepsis. There are several laboratory tests to diagnose neonatal sepsis, including Immature Total (IT) Ratio, C-Reactive Protein (CRP), Procalcitonin (PCT). The sensitivity of the three examinations is quite good, I/T ratio has shown a sensitivity of $88.46 \%$; and specificity of $81.48 \%$, CRP has sensitivity of $88.5 \%$, specificity of $83.3 \%$, and PCT has sensitivity of $92.6 \%$ and specificity of $97.5 \%$. Procalcitonin is a very specific and sensitive indicator of neonatal sepsis, which can only be examined after the baby is 3 days old or more (Darnifayanti et al., 2015; Loni et al., 2016; Memar et al., 2017). Unfortunately, all of the laboratory procedure mentioned above require high cost and not readily available in every healthcare facilities, especially in peripheral areas.

Complete Blood Count (CBC) is a simple and affordable examination in newborn babies to find signs of infection. This examination is almost always available at peripheral health facilities (limited facilities) in Indonesia. Immune responses of circulating leukocytes to numerous stressful events are characterized by raised neutrophil count and minimized lymphocyte count. The increase in neutrophil show response to microbial infection, and they quickly migrate to the influenced region. At the same time, they play an active role in phagocytosis, release of cytokine, and T-cell activation. For this reason, these counts might be used as diagnostic markers of microorganism infection (Can et al., 2017).

Changes in the number of leukocytes, particularly neutrophils and lymphocytes, are also found in a variety of infectious and inflammatory conditions, such as pneumonia, viral infections, bacterial infections, and sepsis (Kartal et al., 2017; Zhao et al., 2017; Holub et al., 2012; Gurol et al., 2015). Omran et al. (2017) found that there were significant differences in neutrophil-lymphocyte count ratio (NLCR) between patient groups with neonatal sepsis and control group with sensitivity of $80 \%$ and specificity of $57.1 \%$. Meanwhile, Ozdemir et al. (2017) found that the NLCR could detect advanced onset neonatal sepsis with a sensitivity of $73.1 \%$ and a specificity of $78.7 \%$.

Based on several pre-existing studies, NLCR is potential to be one of indicator in diagnosing neonatal sepsis. Therefore, the aim of this study is to determine the sensitivity and specificity of NLCR in neonatal sepsis. 


\section{Materials and Methods}

This study was retrospective analytic study, was conducted in Perinatology Division Sanglah hospital. Data was collected from medical records from April 2018 to September 2018. The inclusion criteria was neonates with diagnosis sepsis. Neonates, who experienced immune system disorders, immunodeficiency or malignancy, congenital anomalies or had incomplete medical record data were excluded.

Research subjects were neonates with sepsis (early and late onset sepsis). Samples were selected by consecutive sampling using a large sample estimation formula for the proportion of a population (Madiyono et al., 2011; Wu et al., 2009). With an error rate set at $5 \%$ so that $\mathrm{Z} \alpha=1.96$, the sensitivity set was 0.75 , research precision was $17.5 \%$, and disease prevalence was 0.347 (Khoshdel et al., 2008; Zadora et al., 2015). The minimal sample size was set as many as 76 subjects.

Approval of the ethical feasibility of the study was given by the research ethics commission of the medical school of Udayana University/ RSUP Sanglah Denpasar with a permit number of 1035/UN14.2.2/PD/KEP/2018. The basic data of the study subjects were gender, gestational age, birth weight and laboratory results in the form of neutrophils, lymphocytes and blood cultures obtained from medical records.

Variable operational definitions: neonatal sepsis is defined as a neonate who have clinical symptoms such as lethargy, decreased suction reflexes, whimpering, irritability, seizures, cardiovascular disorders, hematological disorders, gastrointestinal disorders, disorders respiration, elongated gastric emptying time. Sepsis is a clinical syndrome of systemic diseases accompanied by bacteremia that occurs in the first month of life, with positive blood culture; neutrophil lymphocyte count ratio was obtained from the divide of absolute neutrophils and lymphocytes; blood culture results were obtained based on the culture of the examination of blood sample in laboratory, the nominal measurement scale, in which the measurement results are grouped into two groups that are positive and negative; gestational age is a measure of the New Ballard Score (NBS). Term babies are gestational age from 37 to 42 weeks. Infants born before 37 weeks are considered premature; low birth weight (LBW) is birth weight less than 2,500 grams, very low birth weight (VLBW) is birth weight less than 1,500 grams, extremely low birth weight (ELBW) is birth weight less than 1,000 grams and normal weight at term delivery is 2,500-4,000 grams.

The data obtained are presented in the form of narratives and tables. All statistical analyses were conducted with statistical product and service solutions (SPSS) sofware. Catagorical data were presented in numbers and percentage. Numerical data were in median (minimum-maximum) according to the normality of data distribution. The cut-off point of NLCR was determined by using the receiver operating characteristic (ROC) curve analysis. Sensitivity, specificity, positive predictive value (PPV), negative predictive value (NPV) of NLCR were determined using $2 \times 2$ table.

\section{Results and Discussions}

There were one hundred and eleven neonates with clinically suspected neonatal sepsis hospitalized from April 2018 to September 2018. Twenty-six neonates were excluded from this study: fifteen neonates due to congenital anomalies and twelve due to incomplete data. Eighty-four neonates were analyzed for this study.

There was 46 male subjects and 38 female subjects. From the blood culture examination, the number of study subjects with positive blood culture was 22 subjects and negative blood culture results was 62 subjects. Sex differences in the two groups were almost the same. Median neutrophil count, NLCR in groups with positive blood culture were higher compared to groups with negative blood culture. On the other hand, the median lymphocyte count was higher in the group with negative blood culture compared to the group with positive blood culture. The characteristics of the research subjects are shown in Table 1.

Lim, H., Sukmawati, M., Artana, W. D., Kardana, M., \& Putra, P. J. (2021). Validity of neutrophil lymphocyte count ratio in neonatal sepsis. International Journal of Health Sciences, 5(2), 53-61. https://doi.org/10.29332/ijhs.v5n2.1148 
Table 1

Characteristics of research subjects

\begin{tabular}{lll}
\hline & \multicolumn{2}{l}{ Blood culture } \\
\cline { 2 - 3 } Characteristics & $\begin{array}{l}\text { Positive } \\
(\mathrm{n}=22)\end{array}$ & $\begin{array}{l}\text { Negative } \\
(\mathrm{n}=62)\end{array}$ \\
\hline $\begin{array}{l}\text { Sex, } \mathrm{n}(\%) \\
\text { Boy }\end{array}$ & $12(54.5)$ & $34(54.8)$ \\
Girl & $10(45.5)$ & $28(45.2)$ \\
Gestational age, $\mathrm{n}(\%)$ & & \\
Term & $5(22.7)$ & $19(30.6)$ \\
Preterm & $17(77.3)$ & $43(69.4)$ \\
Birth weight, $\mathrm{n}(\%)$ & & \\
Normal weight & $6(27.3)$ & $17(27.4)$ \\
Low birth weight & $8(36.4)$ & $28(45.2)$ \\
Very low birth weight & $5(22.7)$ & $10(16.1)$ \\
Extremely low birth weight & $3(13.6)$ & $7(11.3)$ \\
Neutrophil (median (min-max)) & $10.2(1.73-23.7)$ & $6.6(1.57-21.5)$ \\
Limphocytes (median (min-max)) & $3.43(0.94-6.65)$ & $4.06(1.72-13.1)$ \\
NLCR (median (min-max)) & $2.94(0.41-14.6)$ & $1.58(0.30-4.20)$ \\
\hline
\end{tabular}

Roc Curve

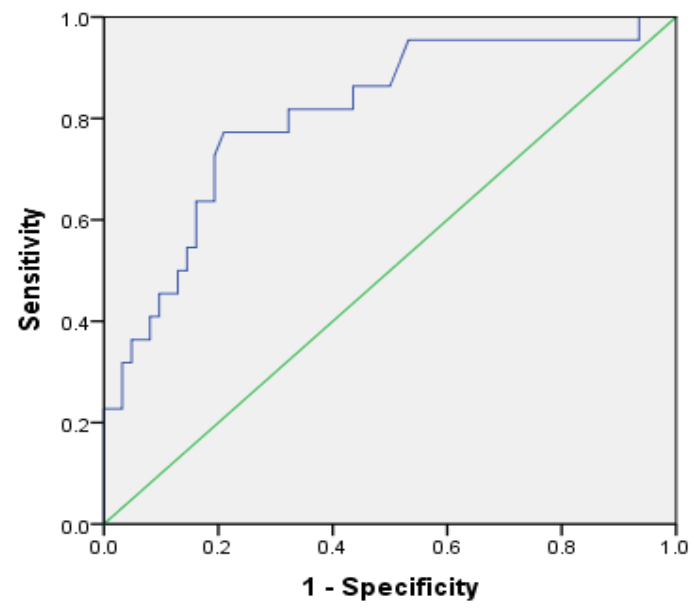

Figure 1. ROC Curve of NLCR in neonatal sepsis.

Figure 1 shows the ROC curve analysis revealed NLCR cut-off point 2.31 in neonatal sepsis, with AUC of $80.9 \%$ (CI 95\% 70.1-91.8). In this study, the use of ROC curve obtained cut-off point 2.31 NLCR has prevalence, sensitivity, specificity, positive predictive value (PPV) and negative predictive value (NPV) of $26.1 \%, 81.8 \%$, $66.1 \%, 46.1 \%$ and $91.1 \%$. Table 2 show the diagnostic values of NLCR in neonatal sepsis.

Table 2

Diagnostic Value of NLCR in neonatal sepsis

\begin{tabular}{lllllll}
\hline \multirow{2}{*}{ NLCR } & \multicolumn{2}{l}{ Blood culture } & Sensitivity (\%) & Specificity (\%) & \multirow{2}{*}{ PPV (\%) } & \multirow{2}{*}{ NPV (\%) } \\
\cline { 2 - 5 } & Positive & Negative & & & \\
\hline$\geq 2.31$ & 18 & 21 & 81.8 & 66.1 & 46.1 & \multirow{2}{*}{91.1} \\
$<2.3 .1$ & 4 & 41 & & & \\
\hline
\end{tabular}




\section{Discussion}

The diagnosis of neonatal sepsis is difficult due to the clinical signs of sepsis often overlapping with other noninfectious causes of systemic inflammation. There is no single reliable test for an early definitive diagnosis of neonatal sepsis and, therefore, there is a continuing search for a new marker to differentiate between sepsis and non-infectious conditions (Shen et al., 2019). Meanwhile a diagnosis using the gold standard in the form of blood culture takes a long time and only has a few positive results. This causes researchers to look for other indicators that can help establish the diagnosis of sepsis.

During infection, bone marrow granulocyte production is reciprocally enhanced over the production of other blood cell types. Enhanced granulocyte production has classically been demonstrated by increased proliferation rates of hematopoietic stem cells and granulopoietic progenitors following a hierarchal pattern of differentiation. In the early stages of an inflammatory response, the predominant cell type infiltrating the tissue is the neutrophil. Neutrophil infiltration into the tissue peaks within the first 6 hours of an inflammatory response, with production of neutrophils in the bone marrow increasing (Melvan et al., 2010; Shane et al., 2017). Neutrophilia and lymphopenia showed bacterial infection. It made neutrophil/lymphocyte ratio increase in sepsis patients (Gurol et al., 2015; Sarraf et al., 2009). In this study, neutrophil/lymphocyte ratio significantly higher in confirmed sepsis than in suspected sepsis. Liu et al. reported the higher neutrophil/lymphocyte ratio associated with more severe sepsis and higher mortality rate. Neutrophil/lymphocyte ratio is integrated into routine blood examination, making it more cost-effective and easier to predict sepsis (Liu et al., 2016).

We performed ROC curve analysis to determine the diagnostic usefulness of NLCR for detecting neonatal sepsis. In the ROC curve, the area under of curve (AUC) NLCR is 83.6 which the examinations can be taken into consideration in diagnosing neonatal sepsis.

NLCR with cut-off point of 2.31 found sensitivity and specificity of $81.8 \%$ and $66.1 \%$, these results were similar to those reported by Omran et al. (2017) who found that NLCR had a sensitivity and specificity of $80 \%$ and $57.1 \%$ in the diagnosis of neonatal sepsis. Meanwhile, different findings also reported by (Ozdemir et al., 2017 \& Can et al., 2017). Ozdemir et al. (2017) with a cut-off point of 1.77 found that the NLCR sensitivity and specificity were $73 \%$ and $78 \%$. This difference could be due to the fact that all samples were preterm and as their birth weights were lower, specificity levels were higher and cut-off point values were lower. There was also late onset sepsis in all the babies, which were made part of the study at the same time. Furthermore, Can et al. (2017) with a 6.76 cut-off point found that the sensitivity and specificity of NLCR were $97.4 \%$ and $100 \%$. This difference can be caused by the different eligibility criteria of the study between this study and the research conducted by them. The subjects in the study were term neonates that divided into 2 groups: sepsis group and healthy neonate control group and their exclusion criteria were stricter in twin, premature or postmature neonates, and small for gestational age (SGA) or large for gestational age (LGA).

In this study, there are negative culture results that have a high NLCR value too, this may be due to the fact that negative culture results may be influenced by several factors, such as the type of bacteria, the number of blood samples taken, the condition of the culture medium, and the administration of antibiotics before taking blood samples. Blood culture is a routine examination for all patients with suspected sepsis, before start the empirical antibiotics (Oyong et al., 2016; Fleischmann-Struzek et al., 2018).

Our study has several limitations, the proven group of sepsis in the study only describes it caused by bacterial, however does not describe any other causes such as viruses. The blood culture conducted in our hospital uses medium that can only grow bacteria and fungi, not other microorganisms. NLCR study with a larger number of subjects needs to be done in the future to get more significant estimation result. In this study there was a higher sensitivity of specificity ( $81.8 \%$ vs $67.7 \%)$ which mean that NLCR examination was good enough for early screening of neonates with sepsis. PPV $46.1 \%$ shows that the probability of neonates with NLCR $\geq 2.31$ having sepsis is $46.1 \%$ while the NPV of $91.1 \%$ shows that the probability of neonates with NLCR $<2.31$ not having sepsis is $91.1 \%$.

Lim, H., Sukmawati, M., Artana, W. D., Kardana, M., \& Putra, P. J. (2021). Validity of neutrophil lymphocyte count ratio in neonatal sepsis. International Journal of Health Sciences, 5(2), 53-61. https://doi.org/10.29332/ijhs.v5n2.1148 


\section{Conclusion}

NLCR is potential to be used in the diagnosis of neonatal sepsis.

\section{Author Contribution}

Heriyanto Lim and Made Sukmawati were involved in planning the work, Heriyanto Lim and Made Sukmawati performed the measurements, Heriyanto Lim processed the experimental data, performed the analysis, drafted the manuscript, designed the figures,calculations and statistical analysis. Made Sukmawati, Wayan Dharma Artana, Made Kardana and Putu Junara Putra aided in interpreting the results and supervised the work of manuscript. All authors discussed the results and commented on the manuscript.

Acknowledgments

We thank our colleagues from Department of Child Health, Medical School of Udayana University/ Sanglah Hospital who provided insight and expertise that greatly assisted the research. 


\section{References}

Alkan Ozdemir, S., Arun Ozer, E., Ilhan, O., \& Sutcuoglu, S. (2018). Can neutrophil to lymphocyte ratio predict late-onset sepsis in preterm infants?.Journal of clinical laboratory analysis, 32(4), e22338. https://doi.org/10.1002/jcla.22338

Can, E., Hamilcikan, Ş., \& Can, C. (2018). The value of neutrophil to lymphocyte ratio and platelet to lymphocyte ratio for detecting early-onset neonatal sepsis.Journal of pediatric hematology/oncology, 40(4), e229-e232. https://doi.org/10.1097/MPH.0000000000001059

Darnifayanti, D., Tjipta, G. D., Rusdidjas, R., \& Lubis, B. M. (2015). Immature-to-total neutrophil ratio as an early diagnostic tool of bacterial neonatal sepsis. Paediatrica Indonesiana,55(3), $153-7$. https://doi.org/10.14238/pi55.3.2015.153-7

Department of Health (2007). Basic Health Research Report (Riskesdas). Jakarta: Health Research and Development Board of the Ministry of Health of the Republic of Indonesia.

Fleischmann-Struzek, C., Goldfarb, D. M., Schlattmann, P., Schlapbach, L. J., Reinhart, K., \& Kissoon, N. (2018). The global burden of paediatric and neonatal sepsis: a systematic review. The Lancet Respiratory Medicine, 6(3), 223-230. https://doi.org/10.1016/S2213-2600(18)30063-8

Gurol, G., Ciftci, I. H., Terzi, H. A., Atasoy, A. R., Ozbek, A., \& Koroglu, M. (2015). Are there standardized cutoff values for neutrophil-lymphocyte ratios in bacteremia or sepsis?.Journal of microbiology and biotechnology, 25(4), 521-525. https://doi.org/10.4014/jmb.1408.08060

Holub, M., Beran, O., Kaspř́ḱková, N., \& Chalupa, P. (2012). Neutrophil to lymphocyte count ratio as a biomarker of bacterial infections. Open Medicine, 7(2), 258-261. https://doi.org/10.2478/s11536-012-0002-3

Kardana, I. M. (2011). Incidence and factors associated with mortality of neonatal sepsis. Paediatrica Indonesiana, 51(3), 144-8. https://doi.org/10.14238/pi51.3.2011.144-8

Kartal, 0., \& Kartal, A. T. (2017). Value of neutrophil to lymphocyte and platelet to lymphocyte ratios in pneumonia. Bratislavske lekarske listy, 118(9), 513-516.

Khoshdel A, Mahmoudzadeh M, Kheiri S, Imani R, Sahahabi G, Saedi E, Taheri E, Motamed R. (2008). Sensitivity and specificity of procalcitonin in diagnosis of neonatal sepsis. Iranian Journal of Pathology, $3(4): 20-37$

Liu, X., Shen, Y., Wang, H., Ge, Q., Fei, A., \& Pan, S. (2016). Prognostic significance of neutrophil-to-lymphocyte ratio in patients with sepsis: a prospective observational study. Mediators of inflammation, 2016. https://doi.org/10.1155/2016/8191254

Loni, R., Sengupta, A., Jaganathan, G., \& Singh, P. K. (2016). The evaluation of C-reactive protein as a screening tool for neonatal sepsis. International Journal of Contemporary Pediatrics, 3(4), 1329-1333.

Madiyono B, Marzuqi SM, Sastroasmoro S, Budiman I, Purwanto SH (2011). Estimated sample size. In: Sastroasmoro S, Ismael S, editors. Dasar-dasar metodologi penelitian klinis. 4th ed. Jakarta: Sagung Seto; 359.

Melvan, J. N., Bagby, G. J., Welsh, D. A., Nelson, S., \& Zhang, P. (2010). Neonatal sepsis and neutrophil insufficiencies. International reviews of immunology, 29(3), 315-348. https://doi.org/10.3109/08830181003792803

Memar, M. Y., Varshochi, M., Shokouhi, B., Asgharzadeh, M., \& Kafil, H. S. (2017). Procalcitonin: the marker of pediatric bacterial infection. Biomedicine \& Pharmacotherapy, 96, 936-943. https://doi.org/10.1016/j.biopha.2017.11.149

Omran, A., Maaroof, A., Saleh, M. H., \& Abdelwahab, A. (2018). Salivary C-reactive protein, mean platelet volume and neutrophil lymphocyte ratio as diagnostic markers for neonatal sepsis. Jornal de Pediatria (Versão em Português), 94(1), 82-87. https://doi.org/10.1016/j.jpedp.2017.07.004

Oyong, N., Anggraini, D., \& Karina, K. (2016). Pola resistensi bakteri penyebab sepsis neonatorum di instalasi perawatan neonatus RSUD arifin achmad riau. Sari Pediatri, 17(6), 435-40.

Sankar, M. J., Agarwal, R., Deorari, A. K., \& Paul, V. K. (2008). Sepsis in the newborn. The Indian Journal of Pediatrics, 75(3), 261-266. https://doi.org/10.1007/s12098-008-0056-Z

Sarraf, K. M., Belcher, E., Raevsky, E., Nicholson, A. G., Goldstraw, P., \& Lim, E. (2009). Neutrophil/lymphocyte ratio and its association with survival after complete resection in non-small cell lung cancer. The Journal of thoracic and cardiovascular surgery, 137(2), 425-428. https://doi.org/10.1016/j.jtcvs.2008.05.046

Shah, B. A., \& Padbury, J. F. (2014). Neonatal sepsis: an old problem with new insights. Virulence, 5(1), 170178. https://doi.org/10.4161/viru.26906

Lim, H., Sukmawati, M., Artana, W. D., Kardana, M., \& Putra, P. J. (2021). Validity of neutrophil lymphocyte count ratio in neonatal sepsis. International Journal of Health Sciences, 5(2), 53-61. https://doi.org/10.29332/ijhs.v5n2.1148 
Shane, A. L., Sánchez, P. J., \& Stoll, B. J. (2017). Neonatal sepsis. The lancet, 390(10104), 1770-1780. https://doi.org/10.1016/S0140-6736(17)31002-4

Shen, C. J., Miao, T., Wang, Z. F., Li, Z. F., Huang, L. Q., Chen, T. T., \& Yan, W. H. (2019). Predictive value of postoperative neutrophil/lymphocyte count ratio for surgical site infection in patients following posterior $\begin{array}{llll}\text { lumbar spinal } & \text { surgery. International immunopharmacology, 74, } & 105705 .\end{array}$ https://doi.org/10.1016/j.intimp.2019.105705

World Health Organisation. (2006).: Neonatal and perinatal mortality: country, regional and global estimates. WHO. cebu: sun.

Wu, J. H., Chen, C. Y., Tsao, P. N., Hsieh, W. S., \& Chou, H. C. (2009). Neonatal sepsis: a 6-year analysis in a neonatal care unit in Taiwan. Pediatrics \& Neonatology, 50(3), 88-95. https://doi.org/10.1016/S18759572(09)60042-5

Zadora, P., Dabrowski, W., Czarko, K., Smolen, A., Kotlinska-Hasiec, E., Wiorkowski, K., ... \& Trojanowski, T. (2015). Preoperative neutrophil-lymphocyte count ratio helps predict the grade of glial tumor-a pilot study. Neurologia i neurochirurgia polska, 49(1), 41-44. https://doi.org/10.1016/j.pjnns.2014.12.006

Zhao, Z., Liu, J., Wang, J., Xie, T., Zhang, Q., Feng, S., ... \& Zhong, B. (2017). Platelet-to-lymphocyte ratio (PLR) and neutrophil-to-lymphocyte ratio (NLR) are associated with chronic hepatitis B virus (HBV) infection. International immunopharmacology, 51, 1-8. https://doi.org/10.1016/j.intimp.2017.07.007 


\section{Biography of Authors}

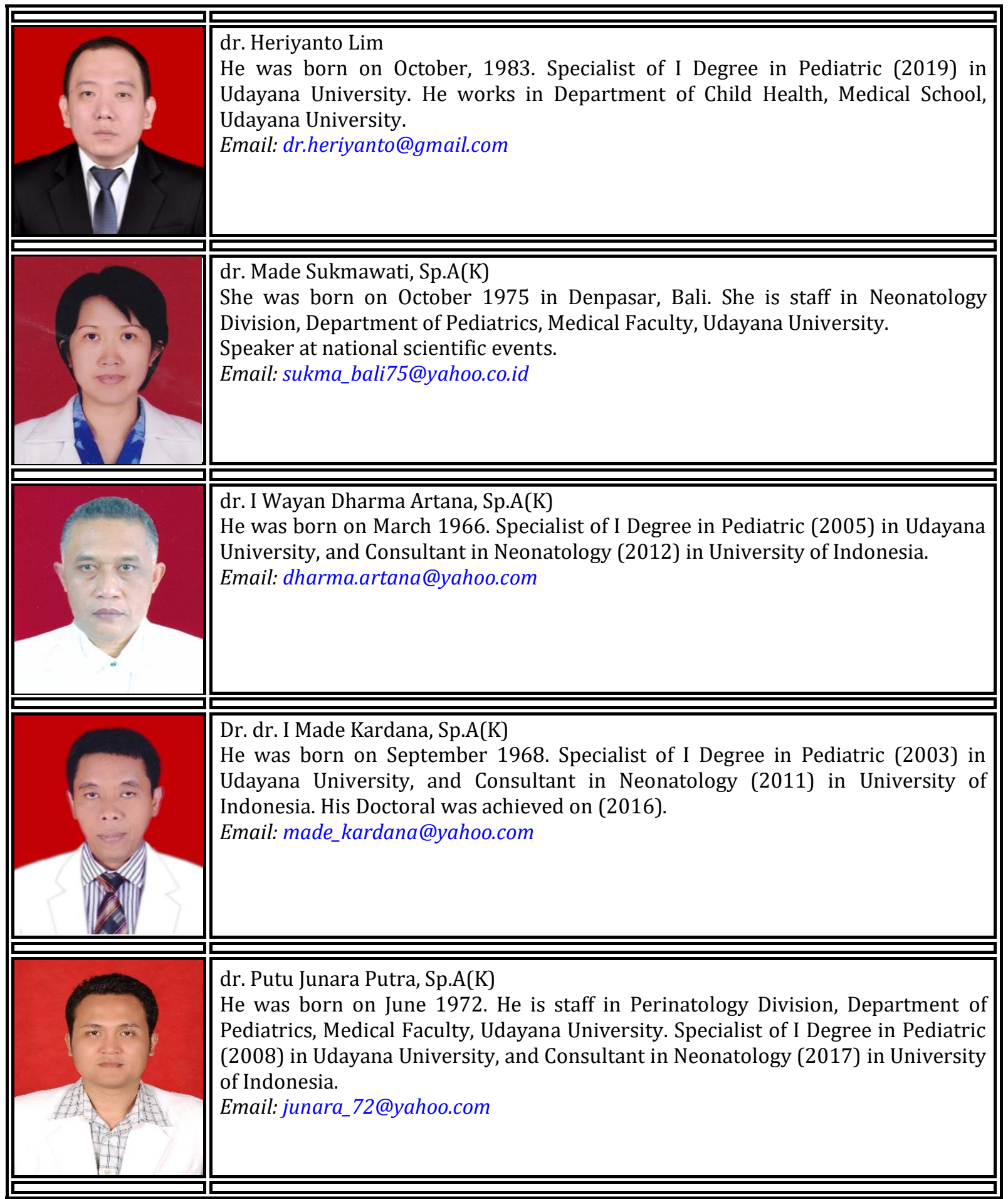

Lim, H., Sukmawati, M., Artana, W. D., Kardana, M., \& Putra, P. J. (2021). Validity of neutrophil lymphocyte count ratio in neonatal sepsis. International Journal of Health Sciences, 5(2), 53-61. https://doi.org/10.29332/ijhs.v5n2.1148 